\title{
Pregnancy outcome at 24-31 weeks' gestation: mortality
}

\author{
U WARIYAR, S RICHMOND, AND E HEY
}

Regional Perinatal Mortality Survey, Northern Regional Health Authority, Newcastle upon Tyne

SUMMARY A study of all the mothers in the Northern region in 1983 whose pregnancies ended at between 24 and 31 weeks' gestation was undertaken. These pregnancies accounted for $1 \cdot 3 \%$ of all the births and $44 \%$ of all the fetal and neonatal deaths in pregnancies that lasted more than 23 weeks. Most of the 389 singleton deliveries without malformations between 24 and 31 weeks were caused by spontaneous premature labour $(n=119,31 \%)$, placental abruption $(n=79,20 \%)$, pre-eclampsia $(n=56,14 \%)$, and premature rupture of membranes $(n=48,12 \%)$. The percentages of babies alive at the onset of delivery who survived the neonatal period were 66,84 , 78 , and 73, respectively and the percentages of neonatal survivors with severe disabilities were $19,13,3$, and 6 , respectively. A further $65(17 \%)$ of these babies died before the onset of labour for no obvious reason. The mode of delivery did not correlate with the outcome once the period of gestation at delivery was taken into account.

The results highlight the inadequacy of the perinatal mortality index currently used in the United Kingdom, which identified 10.7 deaths $/ 1000$ registered births in $1983 ; 20 \%$ of the babies delivered at 24-31 weeks were excluded by this index because the birth went unregistered, as were $21 \%$ of all the babies born alive who died before discharge. An index that accounted for all babies weighing $500 \mathrm{~g}$ or more at birth irrespective of the period of gestation, and all neonatal (0-27 days) deaths, would be more appropriate and would bring reporting more into line with recommended international practice.

At the request of interested clinicians, the Northern Regional Health Authority started a collaborative survey of perinatal mortality in $1980 .^{1}$ The survey was initially limited to stillbirths and early neonatal deaths, but later expanded to include late neonatal deaths; more recently late fetal deaths (after 21 weeks' gestation) have been included.

From the outset it was clear that as perinatal mortality fell pregnancies ending before 32 weeks' gestation were accounting for an increasing percentage of all perinatal deaths. Furthermore, even in pregnancies ending before 32 weeks' gestation, developments in neonatal care were transforming the outlook for babies who were born alive. Though intensive care was, however, undoubtedly reducing the number of early neonatal deaths, it was not clear whether it was preventing or merely delaying the deaths of some of the smaller babies. There was also increasing concern that many of the long term survivors might be severely disabled. A decision was therefore made when the survey was first started to monitor the long term outcome of some of the more vulnerable survivors.

A detailed review was undertaken of all pregnancies in the Northern region in 1983 in which delivery had occurred at 24-31 weeks' gestation. Some additional data were also collected about all pregnancies that resulted in a registerable birth in which the baby had weighed $1500 \mathrm{~g}$ or less at delivery whatever the period of gestation. These data on babies of $<32$ weeks' gestation and $<1500 \mathrm{~g}$ birth weight were then reviewed together with information on the outcome of all deliveries to mothers normally resident in the region, using information provided by the regional perinatal mortality survey. The study is the outcome of a major voluntary effort by all the consultant obstetricians and paediatricians in the region. All could justly claim part authorship of the report: those whose names have been attached have merely assumed responsibility for the analysis of 
mortality, and for coordinating the assessment of survivors. The latter review forms the second report. $^{2}$

\section{Subjects and methods}

The Northern Regional Health Authority serves the whole of the north of England including the scattered rural communities of Northumberland, Durham, and Cumbria and the urban metropolitan counties of Tyne and Wear, and Cleveland. At the time of the survey 21 consultant obstetric units and five independent general practitioner units provided maternity services for a total population of just over 3000000 .

The obstetric records of all mothers normally resident in the region who delivered at 24-31 weeks' (168-223 days) gestation, and the paediatric records of their babies, were examined. Numerous sources were used to ensure that all cases were recorded, and as an additional safeguard the details of all pregnancies recorded as ending at between 20 and 34 weeks' gestation and of all babies weighing less than $1501 \mathrm{~g}$ at birth were checked to ensure that gestational age was as stated. The admission registers of all gynaecology departments, delivery suites, and neonatal nurseries in the region were checked by a member of the team. Necropsy records were checked, and a particularly careful search was made for any aborted fetuses that had undergone necropsy. Lists of children were obtained from consultant paediatricians, community medical personnel, community nursing officers, and the regional child health computer system. The Regional Perinatal Mortality Register ${ }^{1}$ provided information about all perinatal deaths.

\section{CASE NUMBERS}

As soon as all the cases had been identified a cross check was undertaken with the data available to the Office of Population Censuses and Surveys (OPCS) and the Department of Health and Social Security (DHSS). The OPCS had identified three live births weighing $<500 \mathrm{~g}, 100$ live births weighing 500 $999 \mathrm{~g}$, and 210 weighing $1000-1499 \mathrm{~g}$; the regional survey had identified two, 110 , and 208 , respectively. Transcription errors may have caused some problems with the data available to the OPCS, but part of the discrepancy was probably because no information was available about birth weight for 40 of the live births registered with the OPCS, and probably a disproportionate number of the smallest and illest babies were not weighed at birth. Data from the OPCS suggested that neonatal survival for liveborn babies who weighed less than $1000 \mathrm{~g}$ was 39 of $103(38 \%)$, and the figure given by the DHSS, based on LHS $27 / 1$ returns, was 42 of $103(41 \%)$; the regional survey gave a validated figure of $49 / 112(44 \%)$.

BIRTH WEIGHTS

Discrepancies were occasionally encountered between the weight recorded in the obstetric notes and the weight recorded in the delivery suite register, the paediatric notes, and the nursery admission book, both for the babies who died, and for the survivors. Figures were frequently misread or transposed. The recording of weight of babies born dead was particularly inaccurate and it was clear from internal evidence that the recorded weight occasionally included the weight of the placenta as well as that of the fetus for some of the smaller babies. Registered weight of stillbirths did not always agree with the weight originally recorded in the case notes. Very small babies who underwent necropsy were measured more often than they were weighed. Some of the smaller babies were neither weighed nor measured.

\section{GESTATION}

The recording of the period of gestation was even more inaccurate. Paediatric estimates of gestation times were rejected because no paediatric scheme for assessing gestation has ever been validated in babies born at less than 32 weeks' gestation. The estimates of the period of gestation used in this study are based on the antenatal recording of menstrual history and of uterine size at booking, together with any documentary evidence about quickening. All estimates were verified because errors had sometimes crept into the calculations in the case notes. Ultrasound information was used to estimate gestation in those pregnancies where the menstrual history was unreliable, but it was only used to modify the expected date of delivery in other cases where a reliable ultrasonographic estimate of fetal size at 12-18 weeks' gestation gave an estimate that differed from the menstrual estimate by more than 14 days. In the few pregnancies in which no reliable information was available or where it was difficult to reconcile two different estimates of gestation, an independent assessor was asked to determine gestation from a combination of the obstetric data, the information gained at necropsy, or clinical information regarding the child's neurological maturity at birth supplemented by information about when the baby first developed a reliable coordinated sucking and swallowing reflex. Information regarding the child's postneonatal progress was kept from the assessor to minimise potential bias. 


\section{CLASSIFICATION OF DEATH}

All deaths were classified using a version of the scheme first proposed by Wigglesworth. ${ }^{3}$ The obstetric factor most likely to have initiated the train of events leading to death was also assessed using a recently revised version of the classification used by Sir Dugald Baird ${ }^{4}$ to analyse the data from the National Perinatal Mortality Survey of March $1958 .^{5}$

\section{Results}

There were 39117 registered live births and 233 registered stillbirths in 1983, but 10 of the registered live births (who all died within a day) were delivered before 24 weeks' gestation and the survey identified a further 101 babies whose births were not registered because there was never any clear sign of life after delivery at 24-27 weeks' gestation.

The impact of antepartum and intrapartum fetal death, and of early and late neonatal death on the babies of 24-31 weeks' gestation are shown in fig 1, and table 1 shows the causes of death. ${ }^{3}$ The 496 babies in fig 1 and table 1 represent $1 \cdot 25 \%$ of all births to mothers in the region in 1983 for whom pregnancy lasted more than 23 weeks. The deaths ascribed to 'problems of prematurity' in table 1 were all caused by pulmonary immaturity or by hyaline membrane disease (surfactant deficiency) or its late consequencies (for example, bronchopulmonary dysplasia) with or without associated periventricular bleeding or confirmed secondary Gram negative bacterial pneumonia acquired while receiving respiratory support. In this classification ${ }^{3}$ any death from a known fetal or neonatal cause (other than one obviously caused by immaturity) was classified as 'miscellaneous': the deaths included under this heading were 11 of infection, four of rhesus isoimmunisation, two of persistent transitional circulation, and one of necrotising enterocolitis.

The underlying obstetric factors that were thought to have set in train the events leading to the 248 fetal and neonatal deaths ${ }^{4}$ are shown in fig 2. Maternal factors were identified in 13 of these deaths (in association with uterine abnormality, maternal illness, hypertension or renal disease antedating pregnancy, and symptomatic or asymptomatic maternal infection). The four deaths of rhesus isoimmunisation, the death of twin to twin transfusion, and the death caused by mechanical difficulty (cervical trapping of the head in an unattended breech delivery weighing $2200 \mathrm{~g}$ ) have been grouped with the deaths due to maternal factors in fig 2 .

\section{LETHAL MALFORMATIONS}

Twenty malformed babies of 24-31 weeks' gestation were classified as dead at birth, and a further eight died during the first week of life. Half the babies born dead were delivered before 28 weeks' gestation and were therefore unregistered; three of these were
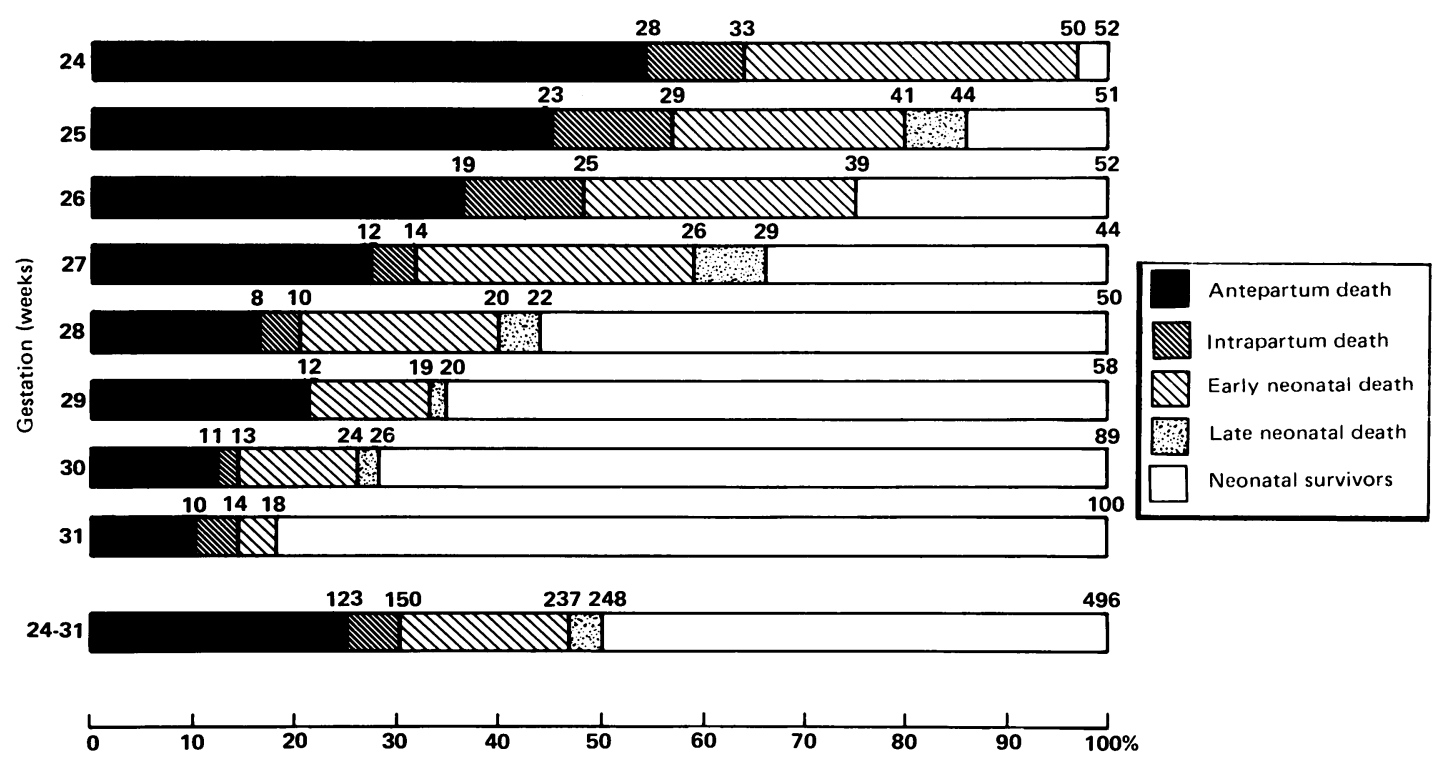

Fig 1 The association between gestational age and the risk of antepartum, intrapartum, early (0-6 day), and late (7-27 day) neonatal death in the 496 babies of 24-31 weeks' gestation at delivery. 
Table 1 Causes of fetal and neonatal death in babies of 24-31 weeks' gestation

\begin{tabular}{|c|c|c|c|c|c|c|c|c|c|}
\hline \multirow{2}{*}{$\begin{array}{l}\text { Gestation } \\
\text { (weeks) }\end{array}$} & \multicolumn{2}{|c|}{ No of births } & \multicolumn{5}{|c|}{ Causes of death (singleton and plural births) } & \multicolumn{2}{|c|}{ Neonatal survivors } \\
\hline & $\begin{array}{l}\text { Singleton } \\
\text { births }\end{array}$ & $\begin{array}{l}\text { Plural } \\
\text { births }\end{array}$ & Malformation & $\begin{array}{l}\text { Antepartum } \\
\text { death }\end{array}$ & $\begin{array}{l}\text { Intrapartum } \\
\text { anoxia with or } \\
\text { without trauma }\end{array}$ & $\begin{array}{l}\text { Problems of } \\
\text { prematurity }\end{array}$ & $\begin{array}{l}\text { Miscellaneous } \\
\text { causes }\end{array}$ & $\begin{array}{l}\text { Singleton } \\
\text { births }\end{array}$ & $\begin{array}{l}\text { Plural } \\
\text { births }\end{array}$ \\
\hline $\begin{array}{l}24 \\
25 \\
26 \\
27 \\
28 \\
29 \\
30 \\
31\end{array}$ & $\begin{array}{l}36(7) \\
46(8) \\
44(4) \\
40(5) \\
42(2) \\
48 \\
77 \\
78\end{array}$ & $\begin{array}{r}16 \\
5 \\
8 \\
4 \\
8 \\
10 \\
12 \\
22\end{array}$ & $\begin{array}{l}7(3) \\
0 \\
2 \\
1 \\
6 \\
4 \\
5 \\
3\end{array}$ & $\begin{array}{r}19(7) \\
22(7) \\
17(3) \\
11(4) \\
8(2) \\
10(1) \\
9 \\
8\end{array}$ & $\begin{array}{l}5(2) \\
6 \\
5 \\
4 \\
2 \\
1 \\
3 \\
4\end{array}$ & $\begin{array}{r}17(2) \\
13 \\
12 \\
12 \\
6 \\
3 \\
4 \\
1\end{array}$ & $\begin{array}{l}2 \\
3 \\
3 \\
1 \\
1 \\
0 \\
2 \\
5 \\
2\end{array}$ & $\begin{array}{r}1 \\
4 \\
11 \\
13 \\
24 \\
31 \\
54 \\
60\end{array}$ & $\begin{array}{r}1 \\
3 \\
2 \\
2 \\
4 \\
7 \\
9 \\
22\end{array}$ \\
\hline Total & $411(26)$ & $85(8)$ & $28(4)$ & $104(24)$ & $30(2)$ & $68(2)$ & $18(2)$ & 198 & 50 \\
\hline
\end{tabular}

Numbers of babies weighing less than $500 \mathrm{~g}$ shown in parentheses.

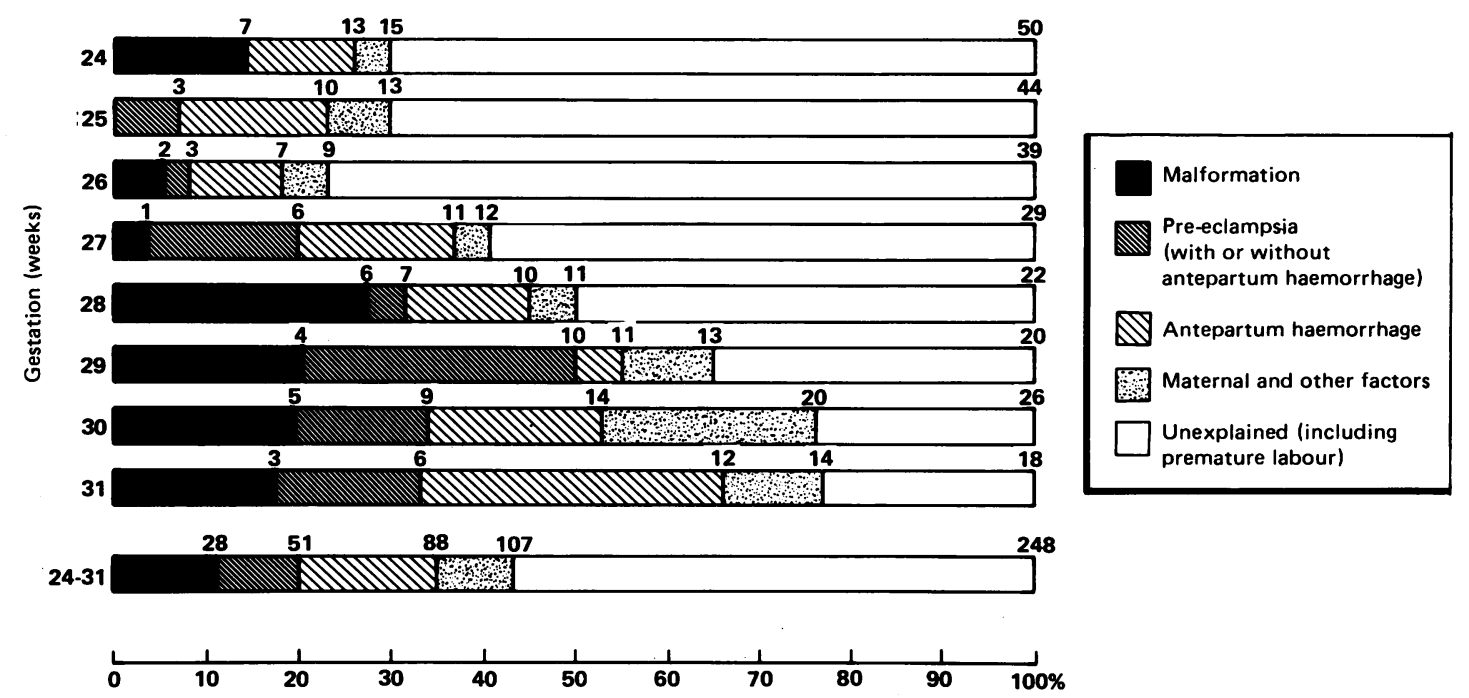

Fig 2 Obstetric antecedents of fetal and neonatal death in the 248 babies of 24-31 weeks' gestation at delivery.

legal terminations of pregnancy for known fetal abnormalities, and six of the 28 babies were twins. Thirteen had neural tube defects and four had bilateral renal agenesis or dysplasia.

\section{SINGLETON PREGNANCIES WITHOUT MALFORMATIONS}

An analysis was undertaken to see to what extent the reason precipitating delivery (tables 2 and 3 ) or the mode of delivery influenced outcome as judged by neonatal survival, or by long term survival without disability two years after birth ${ }^{2}$ in babies of 24-31 weeks' gestation.

\section{Pre-eclampsia}

Twenty three percent (13 of 56) of the babies were born dead, $27 \%$ ( 12 of 45 ) of the babies who were alive at the onset of labour or delivery died before the age of 2 years or survived with severe disability, and one neonatal survivor was severely disabled. Six of the deaths that were associated with preeclampsia were also associated with antepartum haemorrhages.

\section{Antepartum haemorrhage}

In the absence of pre-eclampsia this was usually caused by placental abruption but was occasionally associated with placenta praevia (seven mothers and three deaths). Thirty three percent (26 of 79) of the babies were born dead, $27 \%$ ( 15 of 55 ) of the babies who were alive at the onset of labour or delivery 
Table 2 The association between gestation and $<28$ day mortality in singleton babies without malformations

\begin{tabular}{|c|c|c|c|c|c|c|c|c|c|c|c|c|c|c|}
\hline \multirow{3}{*}{$\begin{array}{l}\text { Gestation } \\
\text { (weeks) }\end{array}$} & \multicolumn{14}{|c|}{ Factor precipitating delivery } \\
\hline & \multicolumn{2}{|c|}{$\begin{array}{l}\text { Pre-eclampsia } \\
\text { with or without } \\
\text { antepartum } \\
\text { haemorrhage }\end{array}$} & \multicolumn{2}{|c|}{$\begin{array}{l}\text { Antepartum } \\
\text { haemorrhage }\end{array}$} & \multicolumn{2}{|c|}{$\begin{array}{l}\text { Premature } \\
\text { rupture of } \\
\text { membranes }\end{array}$} & \multicolumn{2}{|c|}{$\begin{array}{l}\text { Spontaneous } \\
\text { premature } \\
\text { labour }\end{array}$} & \multicolumn{2}{|c|}{$\begin{array}{l}\text { Maternal } \\
\text { factors }\end{array}$} & \multicolumn{2}{|c|}{$\begin{array}{l}\text { Unexplained } \\
\text { antepartum } \\
\text { death }\end{array}$} & \multicolumn{2}{|l|}{ Total } \\
\hline & $\begin{array}{l}\text { No of } \\
\text { deaths }\end{array}$ & $\begin{array}{l}\text { Total } \\
\text { No }\end{array}$ & $\begin{array}{l}\text { No of } \\
\text { deaths }\end{array}$ & $\begin{array}{l}\text { Total } \\
\text { No }\end{array}$ & $\begin{array}{l}\text { No of } \\
\text { deaths }\end{array}$ & $\begin{array}{l}\text { Total } \\
\text { No }\end{array}$ & $\begin{array}{l}\text { No of } \\
\text { deaths }\end{array}$ & $\begin{array}{l}\text { Total } \\
\text { No }\end{array}$ & $\begin{array}{l}\text { No of } \\
\text { deaths }\end{array}$ & $\begin{array}{l}\text { Total } \\
\text { No }\end{array}$ & $\begin{array}{l}\text { No of } \\
\text { deaths }\end{array}$ & $\begin{array}{l}\text { Total } \\
\text { No }\end{array}$ & $\begin{array}{l}\text { No of } \\
\text { deaths }\end{array}$ & $\begin{array}{l}\text { Total } \\
\text { No }\end{array}$ \\
\hline $\begin{array}{l}24 \\
25 \\
26 \\
27 \\
28 \\
29 \\
30 \\
31\end{array}$ & $\begin{array}{l}0 \\
3 \\
1 \\
5 \\
1 \\
4 \\
4 \\
3\end{array}$ & $\begin{array}{r}0 \\
3 \\
1 \\
9 \\
4 \\
8 \\
17 \\
14\end{array}$ & $\begin{array}{l}4 \\
7 \\
4 \\
4 \\
3 \\
1 \\
4 \\
6\end{array}$ & $\begin{array}{r}4 \\
8 \\
8 \\
9 \\
5 \\
8 \\
19 \\
18\end{array}$ & $\begin{array}{l}1 \\
5 \\
2 \\
1 \\
1 \\
0 \\
1 \\
2\end{array}$ & $\begin{array}{r}2 \\
5 \\
4 \\
3 \\
6 \\
6 \\
7 \\
15\end{array}$ & $\begin{array}{l}8 \\
9 \\
8 \\
7 \\
5 \\
2 \\
1 \\
0\end{array}$ & $\begin{array}{r}8 \\
12 \\
13 \\
9 \\
19 \\
15 \\
20 \\
23\end{array}$ & $\begin{array}{l}3 \\
3 \\
4 \\
1 \\
1 \\
2 \\
5 \\
1\end{array}$ & $\begin{array}{l}3 \\
3 \\
4 \\
1 \\
1 \\
3 \\
6 \\
1\end{array}$ & $\begin{array}{r}14 \\
15 \\
13 \\
8 \\
4 \\
4 \\
3 \\
4\end{array}$ & $\begin{array}{r}14 \\
15 \\
13 \\
8 \\
4 \\
4 \\
3 \\
4\end{array}$ & $\begin{array}{l}30 \\
42 \\
32 \\
26 \\
15 \\
13 \\
18 \\
16\end{array}$ & $\begin{array}{l}31 \\
46 \\
43 \\
39 \\
39 \\
44 \\
72 \\
75\end{array}$ \\
\hline Total & 21 & 56 & 33 & 79 & 13 & 48 & 40 & 119 & 20 & 22 & 65 & 65 & 192 & 389 \\
\hline
\end{tabular}

Table 3 Mortality and morbidity associated with the factor precipitating delivery in singleton babies without malformations

\begin{tabular}{|c|c|c|c|c|c|}
\hline \multirow[t]{2}{*}{ Outcome of pregnancy } & \multicolumn{5}{|c|}{ Factor precipitating delivery } \\
\hline & $\begin{array}{l}\text { Pre-eclampsia with or } \\
\text { without antepartum } \\
\text { haemorrhage }\end{array}$ & $\begin{array}{l}\text { Antepartum } \\
\text { haemorrhage }\end{array}$ & $\begin{array}{l}\text { Premature rupture } \\
\text { of membranes }\end{array}$ & $\begin{array}{l}\text { Spontaneous } \\
\text { premature labour }\end{array}$ & $\begin{array}{l}\text { Other } \\
\text { maternal } \\
\text { factors }\end{array}$ \\
\hline Antepartum death & 11 & 24 & 0 & 0 & 5 \\
\hline Intrapartum death & 2 & 2 & 0 & 11 & 2 \\
\hline Neonatal death & 8 & 7 & 13 & 29 & 13 \\
\hline Postneonatal death & 1 & $2(2)$ & $5(1)$ & $7(5)$ & 0 \\
\hline Long term survivors & $34(1)$ & $44(4)$ & $30(1)$ & $72(10)$ & 2 \\
\hline Total & $56(1)$ & $79(6)$ & $48(2)$ & $119(15)$ & 22 \\
\hline
\end{tabular}

Numbers of babies with severe perinatal disabilities shown in parentheses.

died before the age of 2 years or survived with severe disability, and $13 \%$ (six of 46 ) of the neonatal survivors had severe disabilities.

\section{Premature rupture of membranes}

Rupture of the membranes without any immediate evidence of progressive labour was associated with 13 neonatal and five postneonatal deaths. Five of the neonatal deaths were due to group $B \quad \beta$ haemolytic streptococcal pneumonia and septicaemia, and secondary pulmonary hypoplasia associated with prolonged loss of liquor occurred in two of the others (not all the babies were examined for this at necropsy). Forty percent (19 of 48) of the liveborn babies died before the age of 2 years or survived with severe disabilities, but only $6 \%$ (two of 35) of the neonatal survivors had severe disabilities.

\section{Unexplained spontaneous premature labour}

Forty seven percent (57 of 119) of the babies who were alive at the onset of labour died before the age of 2 years or survived with disabilities, and 19\% (15 of 79) of the neonatal survivors had severe disabilities.

\section{Other maternal factors}

There were six deaths caused by symptomatic or asymptomatic infection, and four deaths caused by rhesus isoimmunisation. Two mothers went into labour after undergoing laparotomies (one for appendicitis and the other for intestinal obstruction caused by adhesions), and the second of these babies survived without disability. Two babies were born dead and one survived caesarean delivery for severe maternal hypertension. One other baby was born dead following a maternal diabetic crisis, and another died of pulmonary immaturity shortly after delivery, when labour had started at 26 weeks' gestation in a mother with a double uterus and a past history of midtrimester miscarriage. Five early neonatal deaths at 24-26 weeks' gestation associated with unequivocal cervical incompetence have been included under this heading in table 2 (but classified 
as unexplained in fig 2 because the cause of the cervical incompetence was unknown).

\section{Mode of delivery}

We reviewed the association between mode of delivery and long term outcome in singleton pregnancies (excluding those in which the baby was lethally malformed or died before the onset of labour). Seventy two percent of the babies delivered by caesarean section survived to 2 years without severe disability, the prognosis being better when delivery was undertaken before rather than after the onset of labour (47 of 59 compared with 12 of 23). Fifty seven percent of the breech ( 25 of 44$)$ and $52 \%$ of the vertex ( 82 of 159) vaginal births survived without severe disabilities. Twelve of the latter were delivered with forceps; all survived, but three had severe disabilities. One other baby survived compound presentation and delivery unscathed at 30 weeks' gestation. These figures give the impression that the outlook is bet'er after operative abdominal delivery, but most of the babies delivered by caesarean section were relatively mature; only 18 (22\%) were less than 29 weeks' gestation. An analysis taking gestation into account showed that outcome was only marginally better for babies delivered by caesarean section (table 4).

PLURAL PREGNANCIES WITHOUT MALFORMATIONS Labour started spontaneously at 25 weeks' gestation in the only triplet pregnancy. Two of the triplets died in the early neonatal period, and the other baby is a severely disabled long term survivor. There were a further 41 twin pregnancies. Thirty two of the 82 babies died in the perinatal period $(12$ were born dead before 28 weeks' gestation) and there was one

Table 4 Long term survival without disability in singleton babies alive at the onset of labour or at delivery and without malformations

\begin{tabular}{|c|c|c|c|c|}
\hline \multirow{3}{*}{$\begin{array}{l}\text { Gestation } \\
\text { (weeks) }\end{array}$} & \multicolumn{4}{|c|}{ Mode of delivery } \\
\hline & \multicolumn{2}{|l|}{ Vaginal } & \multicolumn{2}{|l|}{ Caesarean } \\
\hline & $\begin{array}{l}\text { No of } \\
\text { survivors }\end{array}$ & $\begin{array}{l}\text { Total } \\
\text { No }\end{array}$ & $\begin{array}{l}\text { No of } \\
\text { survivors }\end{array}$ & $\begin{array}{l}\text { Total } \\
\text { No }\end{array}$ \\
\hline 24 & 1 & 14 & 0 & 0 \\
\hline 25 & 2 & 21 & 0 & 2 \\
\hline 26 & 8 & 21 & 0 & 4 \\
\hline 27 & 6 & 21 & 3 & 7 \\
\hline 28 & 16 & 26 & 5 & 5 \\
\hline 29 & 21 & 27 & 7 & 8 \\
\hline 30 & 24 & 33 & 22 & 29 \\
\hline 31 & 29 & 40 & 22 & 27 \\
\hline Total & 107 & 203 & 59 & 82 \\
\hline
\end{tabular}

late neonatal death (table 1). Six of the perinatal deaths were caused by lethal malformation. Perinatal mortality in twin babies (39\%) was less than in singleton pregnancies $(49 \%)$. Follow up data ${ }^{2}$ also showed a reduction in the incidence of disability in twins surviving the neonatal period (three of 49 compared with 24 of 198), but this was not significant.

Unexplained spontaneous premature labour (22 mothers) and premature rupture of membranes followed later by the onset of spontaneous labour (six mothers) were commoner in twin pregnancies than in singleton ones. Fifteen of these babies died in the perinatal period, and two later in infancy. Two of the 39 survivors are severely disabled. Other complications of pregnancy were less common in twin pregnancies. Four mothers suffered placental abruption: four of the babies died in the perinatal period and one in later infancy, and one of the three long term survivors is severely disabled. One mother with pre-eclampsia of pregnancy lost both her babies in the neonatal period after delivery at 29 weeks' gestation. There were three unexplained antepartum deaths and twin fetal deaths with ascending uterine infection, while one other twin died of complications of the twin to twin transfusion syndrome. The twins born to two mothers at 31 weeks' gestation because of maternal hypertension that antedated pregnancy all survived.

\section{Discussion}

CONTRIBUTION TO TOTAL FETAL LOSS

A review of the outcome of all pregnancies lasting more than 23 weeks in 1983 showed that $44 \%$ of all registered and unregistered fetal deaths, $63 \%$ of all early neonatal deaths, and $44 \%$ of all late neonatal deaths unassociated with lethal malformation occurred to babies born more than eight weeks before full term. Such deaths also accounted for half of all the deaths at any gestation associated with intrapartum anoxia or trauma, or both, in the absence of abruptio placentae and more than half of all the deaths associated with pre-eclampsia, antepartum haemorrhage, infection, and twin pregnancy.

\section{FACTORS CAUSING DELIVERY BEFORE 32 WEEKS}

It is often said that the development of an effective way of preventing or arresting spontaneous premature labour would be the biggest single contribution that could be made to reducing perinatal mortality. While this is true, spontaneous premature labour was responsible for only $29 \%$ of the singleton births (and 19\% of the singleton deaths) at 24-31 weeks' gestation in this study: the contributions of placental 
abruption and other antepartum haemorrhage (19\%), pre-eclampsia $(14 \%)$, other maternal problems $(4 \%)$, unexplained premature rupture of membranes $(12 \%)$, fetal abnormality $(5 \%)$, and rhesus isoimmunisation (1\%) are often overlooked, as is that of totally unexplained antepartum fetal death $(16 \%)$. Delivery was a planned and elective decision in only $14 \%$ (63 of 453 ) of all the mothers delivered before 32 weeks' gestation: the factor responsible for the decision to intervene was antepartum haemorrhage or hypertension (with or without signs of pre-eclampsia) in almost every case, together with supplementary evidence of poor fetal growth on seven occasions. These findings confirm the findings of a study from Oxford of the causes of preterm delivery. ${ }^{6}$

\section{SCOPE FOR IMPROVED CARE}

There were 65 unexplained antepartum singleton deaths (table 2), and it is difficult to see what more could have been done to anticipate the deaths of most of these babies; six normally formed babies were small for gestational age but only one of these weighed $500 \mathrm{~g}$ or more at birth.

It is possible, however, that a few of the 11 antepartum deaths from pre-eclampsia might have been prevented by increased antenatal monitoring, because only three of these babies died before 29 weeks' gestation. General practitioners undertook the obstetric care of many of the women once the first booking visit to hospital was over until about 28 weeks' gestation. Pre-eclampsia often seemed to come on quite abruptly at about the time the women were preparing to return to the hospital clinic for further care, and some of the mothers had not seen a doctor or midwife for more than four weeks at the time of their admissions with severe pre-eclampsia. Enquiry suggested that uncertainty about the exact timing of the transfer back to hospital care and uncertainty about who was responsible for care during the transition period contributed to this oversight. It is at least possible that the onset of pre-eclampsia was sometimes less abrupt than it seemed to be.

Antepartum or intrapartum infection accounted for nine deaths, and postpartum infection for eight deaths (including five babies who became infected while being ventilated). Group B $\beta$ haemolytic streptococci were isolated from all five of the babies with antenatal infections in whom a positive microbiological diagnosis was made, and in each case there was a history of premature rupture of membranes. The resulting infections were uniformally fatal despite immediate treatment with antibiotics. In this series, therefore, lethal group B $\beta$ haemolytic streptococcal infection was identified in a tenth of all the singleton pregnancies in which the membranes had ruptured spontaneously before the onset of labour.

Five babies without malformations weighing $500 \mathrm{~g}$ or more died during labour or in the neonatal period as a result of intrapartum trauma, and 23 of intrapartum anoxia (table 1). Only five of the deaths of anoxia were associated with placental abruption. Few of the babies were monitored electronically during labour, partly because many of the mothers did not reach hospital until they were already in advanced labour, and it is at least possible that some lives could have been saved by increased monitoring and obstetric intervention. Only 18 babies in this study had caesarean deliveries after going into spontaneous labour in the absence of placental abruption and only 12 babies were delivered with forceps.

There is nevertheless nothing in these data to suggest that a general increase in operative delivery would improve outcome. The data in table 4 suggest only marginal benefit from caesarean delivery at any gestation. A larger study might confirm this trend, but this still would not establish that any difference in outcome was caused by the method of delivery itself. The prognosis for long term survival without disability among babies alive at the start of delivery was $73 \%$ among singleton pregnancies complicated by pre-eclampsia or antepartum haemorrhage, but only $54 \%$ in pregnancies complicated by premature rupture of membranes or spontaneous premature labour (table 3). Because pre-eclampsia or antepartum haemorrhage complicated $76 \%$ of the deliveries by caesarean section there can be no way of knowing whether it was the factor that influenced the obstetrician to choose caesarean delivery or the mode of delivery itself that contributed to the improved prognosis. Our conclusion concurs with that reached in the largest single centre study of the role of caesarean delivery in babies of less than 30 weeks' gestation. ${ }^{7}$ Caesarean delivery was offered to $11 \%$ of all the babies of 24-29 weeks' gestation delivered in the Northern region in 1983 (the comparable figure from the Melbourne study being $15 \cdot 6 \%)^{7}$

Improved resuscitation at birth might have saved a few lives. Twenty babies of 24-25 weeks' gestation born without malformations were never offered sustained respiratory support after birth, and a few of these might have survived had such facilities been available. Others who died from secondary complications precipitated by respiratory support after birth (such as pulmonary interstitial emphysema and bronchopulmonary dysplasia) might have survived had artificial surfactant and high frequency ventilation been available. 
PERINATAL MORTALITY

The results of this study highlight the inadequacy of the current method of calculating perinatal mortality in the United Kingdom; $20 \%$ of the babies delivering at 24-31 weeks' gestation (101 of 496) would have been excluded from this study had those pregnancies in which a baby showed no clear sign of life after birth at 24-27 weeks' gestation been excluded from consideration merely because the birth did not legally need to be registered. Similarly, any study that ignored all deaths in babies over six days old would have ignored $21 \%$ ( 23 of 110 ) of the liveborn babies who died before discharge from hospital.

Perinatal mortality in the Northern region in 1983 among registerable births using the definition used by the OPCS was $10 \cdot 7$ deaths $/ 1000$ births (423/39350). Any calculation, however, that took into consideration all pregnancies lasting more than 21 weeks' gestation (in line with the recent report issued by the Royal College of Obstetricians $^{8}$ ) would have produced a figure of $15 \cdot 9 / 1000$ births $(627 / 39544)$ for perinatal mortality because in addition to the 101 babies born dead at 24-27 weeks' gestation (fig 1), 103 babies (including 10 twins) were delivered at 22-23 weeks' gestation, and only seven of these babies were registered as live born. Similarly, any calculation using the definition recommended by the World Health Organisation, ${ }^{9}$ which identifies all babies weighing $500 \mathrm{~g}$ or more at birth irrespective of period of gestation, would have yielded a figure of at least $12 \cdot 6 / 1000$ births $(497 / 39424)^{2}$ - the exact figure being uncertain because some babies of less than 24 weeks' gestation went unweighed. When account is taken of the 46 late neonatal deaths among babies born in the region in 1983, an overall perinatal and late neonatal mortality rate of at least 13.8 deaths $/ 1000$ births is obtained for babies weighing $500 \mathrm{~g}$ or more at birth. Babies of less than 32 weeks' gestation accounted for $45 \%$ of these deaths.

Others have highlighted this issue before. ${ }^{10}$ Survival is becoming increasingly common at 24-27 weeks' gestation, and it is now widely accepted that the clinical limit of viability is nearer to 24 weeks' than 28 weeks' gestation. The method of calculating perinatal mortality currently in use in the United Kingdom has little in its favour (except that it can be used to compare current rates with past data). The definition bears little relation to that recommended by the World Health Organisation and, as low birthweight deaths account for a progressively larger percentage of all deaths, the discrepancy becomes increasingly unacceptable. International comparison is impossible and the lack of data on babies born dead before 28 weeks' gestation renders comparison across this gestational divide meaningless.
A commitment to registering the delivery of every baby born after more than 21 weeks' gestation would give a more appropriate index of fetal loss. It would also serve to acknowledge the sense of loss that parents feel after a late miscarriage. It would need to be accompanied, however, by a commitment to weigh every baby at birth and record the birth weight together with the other confidential particulars collected on every birth at registration. While the present survey managed to obtain this information, the effort that this entailed only serves to highlight the fact that such information will never become generally available until its collection becomes a legal necessity.

The time has come to reform the method of assessment of perinatal mortality in this country, or to tacitly admit by our inaction that it is not a statistic that particularly matters.

This report is published with the agreement of the survey steering group, but we take full responsibility for the content. We thank the obstetricians and paediatricians whose continuing support for the region's collaborative Perinatal Mortality Survey made this study possible. We also thank Mrs M Renwick, the survey coordinator, whose commitment and efficiency made sure that no relevant death went undocumented.

\section{References}

${ }^{1}$ Northern Regional Health Authority Coordinating Group. Perinatal mortality: a continuing collaborative regional survey. Br Med J 1984;288:1717-20.

2 Wariyar U, Richmond S, Hey E. Pregnancy outcome at 24-31 weeks' gestation: neonatal survivors. Arch Dis Child 1989;64: 678-86.

3 Hey EN, Lloyd DJ, Wigglesworth JS. Classifying perinatal death: fetal and neonatal factors. Br J Obstet Gynaecol 1986;93:1212-23.

4 Cole SK, Hey EN, Thomson AM. Classifying perinatal death: an obstetric approach. Br J Obstet Gynaecol 1986;93:1204-11.

5 Baird D, Thomson AM. The survey perinatal deaths reclassified by special clinico-pathological assessment. In: Butler NR, Alberman ED, eds. Perinatal problems. Edinburgh: Churchill Livingstone, 1969:200-10.

6 Rush RW, Keirse MJNC, Howat P, Baum JD, Anderson ABM, Turnbull AC. Contribution of preterm delivery to perinatal mortality. Br Med J 1976;ii:965-8.

7 Kitchen W, Ford GW, Doyle LW, et al. Cesarean section or vaginal delivery at 24-28 weeks' gestation: comparison of survival and neonatal and two-year morbidity. Obstet Gynecol 1985;66:149-57.

8 Working party of the Royal College of Obstetricians and Gynaecologists. Report on fetal viability and clinical practice. London: Royal College of Obstetricians and Gynaecologists, 1985.

9 World Health Organisation. International classification of diseases, ninth revision, 1975. Definitions and recommendations. Geneva: World Health Organisation 1977:763-8.

${ }^{10}$ Whitfield CR, Smith NC, Cockburn F, Gibson AAM. Perinatal related wastage-a proposed classification of primary obstetric factors. Br J Obstet Gynaecol 1986;93:694-703.

Correspondence to Dr U Wariyar, Princess Mary Maternity Hospital, Great North Road, Newcastle upon Tyne NE2 3BD.

Accepted 18 November 1988 